\title{
Analytical Tool for Risk Assessment of Landscape and Urban Planning: Spatial Development Impact Assessment
}

Research article

\author{
David Rehak ${ }^{1 *}$, Michail Senovsky ${ }^{1 \dagger}$, Karol Balog ${ }^{2 \ddagger}$, Jiri Dvorak ${ }^{3 \S}$ \\ 1 VSB - Technical University of Ostrava, Faculty of Safety Engineering, Lumírova 13, 70030 Ostrava-Výškovice, Czech Republic \\ 2 Slovak University of Technology in Bratislava, Faculty of Materials Science and Technology, Paulínska 16, 91724 Trnava, \\ Slovak Republic \\ 3 University of Defence, Faculty of Economics and Management, Kounicova 65, 66210 Brno, Czech Republic
}

Received 05 February 2011 ; accepted 08 April 2011

\begin{abstract}
This article covers the issue of preventive protection of population, technical infrastructure, and the environment against adverse impacts of careless spatial development. In the first section, we describe the relationship between sustainable development and spatial development. This discussion is followed by a review of the current state of spatial development security, primarily at a national level in the Czech Republic. The remainder of the paper features our original contribution which is a tool for risk assessment in landscape and urban planning, the Spatial Development Impact Assessment (SDIA) tool. We briefly review the most significant semi-quantitative methods of risk analysis that were used as a starting point in implementing the tool, and we discuss several of SDIA's salient features, namely, the assessment process algorithm, the catalogue of hazard and asset groups, and the spatial development impact matrix.

Keywords: Landscape and Urban Planning • Sustainable Development $•$ Negative Aspects of Spatial Development $•$ Spatial Development Security $\bullet$ Spatial Development Impact Assessment

(C) Versita Sp. z o.o.
\end{abstract}

\section{Introduction}

There are many adverse effects on population groups in highly industrial and developing societies that result from careless anthropogenic activities. These effects may vary in nature. They may be economic, psychological, or they

*E-mail: david.rehak@vsb.cz

${ }^{\dagger}$ E-mail: michail.senovsky@vsb.cz

¥E-mail: karol.balog@stuba.sk

§E-mail: jiri.dvorak@unob.cz may directly trigger physical health problems. Most notably, in cases where the environment is polluted or damaged during spatial development, there is a direct negative impact on public health [1].

The development of a territory, spatial development as it is termed, is as old as humankind. Humans have always tried to adapt newly settled territories to their needs while also increasing the utility value of these territories; typically, individual residences and other facilities are built in a given area [2]. At present, spatial development is, once again, experiencing a considerable expansion. Pop- 
ulation groups now congregate in large urban agglomerations which continuously expand [3]. As a result, new industrial plants are built and their appropriate placement is a necessary prerequisite for the approval of any spatial development $[4,5]$.

However, recent evidence suggests that there has been increased damage from natural elements in many areas, thus highlighting a significant need for improvement in spatial development [6]. The integration of heavy industry within urban areas, over-mining of mineral resources which causes irreversible damage to important ecosystems, and inadequate placement of large buildings disrupting the character of the landscape are classic examples of anthropogenic activities which have negative effects on social groups.

In addition to creating severe public health concerns (for instance an alteration in the genetic pool of the group), these activities have a severe economic impact. Additional costs need to be covered in order to maintain a classical economic growth rate and restore the environment [7]. Therefore, a model of spatial development that enables a dignified way of living for our generation but also maintains good conditions for future generations is warranted [8-10].

\section{Background}

In this section, we introduce background material and concepts that form the basis of our spatial development security assessment tool. We discuss the concepts of Sustainable and Spatial Development, Security of Spatial Development, and we introduce Semi-Quantitative Methods of Risk Analysis.

\subsection{Sustainable Development and Spatial De- velopment}

Sustainable development has been high on the agenda of many governments as well as that of the public since the 1960's. The first serious warning against extensive economic development that disregards the environment occurred in the tense first half of the 1970's, during the sudden worldwide energy crisis. This significant milestone was the United Nations (UN) Conference on the Human Environment, held in Stockholm in 1972. Principle 13 of the Stockholm Declaration can be considered to be the essence of sustainable development [11]. It states: "In order to achieve a more rational management of resources and thus to improve the environment, states should adopt an integrated and coordinated approach to their development planning so as to ensure that development is com- patible with the need to protect and improve environment for the benefit of their population.".

Another significant milestone in the field of sustainable development is the Concept of Sustainable Development [12] of the Modern World. This concept was developed in 1987, and it represents an alternative model of social development in relation to the dominant industrial economy. Before the birth of this concept, there was no reflection on the natural environmental limits of economic growth. Economic growth was generally considered to arise from increased welfare and successful social development. However, since the 1980's the concept's scope, especially in developed countries, encompasses sustainability and qualitative aspects of development. A well known definition from the Report of the UN Commission on Environment and Development (also known as the Brundtland Report) is as follows: "Sustainable development is development that meets the needs of the present without compromising the ability of future generations to meet their own needs and that does not happen at the expense of other nations."

Spatial Development, on the other hand, is defined from various perspectives in the Literature. It is often understood to be the economic development of a territory in terms of increased revenue generation [13]. Such an understanding is biased and leads to negative consequences.

It is necessary to understand spatial development from a wider perspective. Rather, it should be viewed as a complex development process of territories that includes all their components. The most suitable definition which fits this view has been purported by the Institute of Spatial Development [14]. It is as follows: "The spatial development is a complex development of a territory, which includes the development of all material assets, activities and processes related to the territory and their mutual relations. It is thus a continuous process of development and changes in the utilization of areas, sites, buildings (urban structures) and landscape (natural structures), including their maintenance and protection of values. The goal is the sustainable and balanced development of all the above mentioned components in the territory. The instruments for coordinating the spatial development are mainly spatial planning, regional policy, care of the environment, and care of cultural and natural heritage."

\subsection{Spatial Development Security}

The first strategic document regarding spatial development security in the Czech Republic is the State Environmental Policy of the Czech Republic [15] which defines a consensual framework for mid-term and long-term development of the environmental aspect of sustainable devel- 
opment of the Czech Republic. The second is the Strategy of Sustainable Development of the Czech Republic [16]. This strategy creates a framework for elaborating the materials of conceptual character (departmental policies and action programmes). It is a starting point for strategic decision making within individual departments, interdepartmental cooperation and cooperation among interest groups.

Spatial development in the Czech Republic follows the Act on Spatial Planning and Building Code [17]. The spatial development is carried out in compliance with this Act and on the basis of spatial planning. The function of spatial planning is to assess the policy effects of spatial development, the principles of spatial development, and a spatial plan on a balanced relation between spatial conditions and the environment, economic development and a unity of population living on the territory (hereinafter "assessment of impacts on the sustainable development of territory"). The above mentioned Act is supported by the implementation of regulation on analytical data, planning documents and the way of recording the spatial planning, which amends the terms by assessing their impact on the sustainable development of the territory.

Moreover, the Act on the Protection of Nature and Landscape [18] is a relevant statute for assessing the impact of spatial development on the environment. It states that any concept or intention that, either independently or in connection with other concepts, significantly influences the level of protection or the integrity of sites of European importance (as well as important bird habitats) is the subject of assessment of their impact on these sites and of the extent to which they protect these sites $[19,20]$.

When assessing the consequences of concepts and intentions on the basis of the above mentioned Act, the procedure is followed according to the Act on Environmental Impact [21], which, in compliance with European Union law [22-24], amends the assessment of impacts on the environment and public health as well as the procedures followed by physical entities, legal entities, administrative authorities and territorial self-administration units (municipalities and districts) in the course of assessment. This Act is followed when assessing the impacts on public health and the environment, including the impacts on flora and fauna, ecosystems, soil, rock environment, water, air, climate, landscape, natural resources, corporate property, cultural monuments and their mutual relations and interactions. Thus it is a spatial development impact assessment on population and the environment aimed at providing social and environmental development security. Assessing impacts of spatial development on infrastructure with the aim of providing technical security is not required by any legal standard.
However, it is a very important part of spatial development security [25], which should be taken into consideration within the process of spatial planning.

\subsection{Semi-Quantitative Methods of Risk Anal- ysis}

At present, there are many methods of risk analysis employed in the area of security $[26,27]$, but neither of them is fully suitable for the analysis and assessment of spatial development security. More detailed analyses of the subject matter identified three relevant semi-quantitative methods of risk analysis on which the development of a new tool of spatial development security assessment must be based. These methods are the Fire \& Explosion Index, the Hazard \& Vulnerability Index and the Hazard \& Impact Index.

The Fire \& Explosion Index Method [28] is a step-by-step index system that aims to realistically assess the threat of fire and explosion given a technological facility's potential. The quantitative parameters used in the system are based on historical data obtained from analyzing past accidents and on the preventive measures commonly used in technological practice. The Fire \& Explosion Index provides quantitative measures of possible damage caused by fire or explosion, the identification of equipment which may escalate accidents, and it informs management on the outcomes of the analysis.

The step-by-step analysis of the Fire \& Explosion Index Method is an optimal decision-making algorithm. Its advantages lie in its simplicity and clarity when implementing individual stages of the method. Nevertheless, the method is unsuitable as it is specifically aimed only at a restricted set of hazards, namely fire and explosion. Moreover, another drawback is that its implementation is time consuming.

The Hazard \& Vulnerability Index Method [29] is applied for assessing the impact of accidents on the environment. It is also used for assessing and prioritizing the risks on the territories up to the size of the region. The assessment of larger territorial units would require the implementation of geographic information systems. The method is based on mathematical procedures which provide a clear overview of final index values and subsequent determination of the impact of hazardous substances on the environment. At the same time, the clarity of indexation is supported by the principle of separate indexation for individual environmental elements. Therefore the above mentioned principle is applied not only to the indexation, but also to the classification of negative aspects of spatial development as well as the areas which are impacted. 
The method of preventive military training and environmental impact assessment is called the Hazard \& Impact Index [30]. It is a semi-quantitative method that was developed by the team of Czech environmentalists from 2007 to 2009 as part of the project of the Czech Academy of Sciences Grant Agency. After being completed in the first half of 2010 it underwent practical testing. After successful negotiations with the Czech Ministry of Defence Logistic Section the method was implemented in the Army of the Czech Republic in the form of guidelines in June 2010 [31]. The algorithm used the outcomes of a study of the methods of technological risks analysis based on a semi-quantitative assessment. The final algorithm comprises individual steps which determine the level of risk to the environment caused by military training.

Its advantages are mainly its simplicity, its clarity, and operability when applying the individual stages of the method. Consequently, the assessment algorithm was used when developing the assessment process algorithm, which is the key part of the spatial development environmental impact assessment tool.

\section{Results: Spatial Development Im- pact Assessment Method}

Social, technological and environmental security requires a preventive assessment of all possible risks of planned spatial development and minimizing them prior to the plan's implementation. Spatial development security risk assessment is a rather complicated activity during which it is necessary to consider a large number of various input data and factors.

The SDIA Method is based on the principle of semiquantitative assessment of potential negative aspects of spatial development and the areas of their possible impacts. The aim is to realistically assess the potential hazards resulting from spatial development. The tool was developed in compliance with national legal regulations, and thus the impact assessment process is expected to be accessible both from technological and legislative viewpoints.

\subsection{Assessment Process Algorithm}

We now outline the structure of the Assessment Process Algorithm whose purpose is to assess the impacts of spatial development on population, infrastructure and the environment. This algorithm defines basic relations among individual elements of the process, which are divided into two basic groups: 1) the Group of Hazards, which includes individual negative aspects of spatial

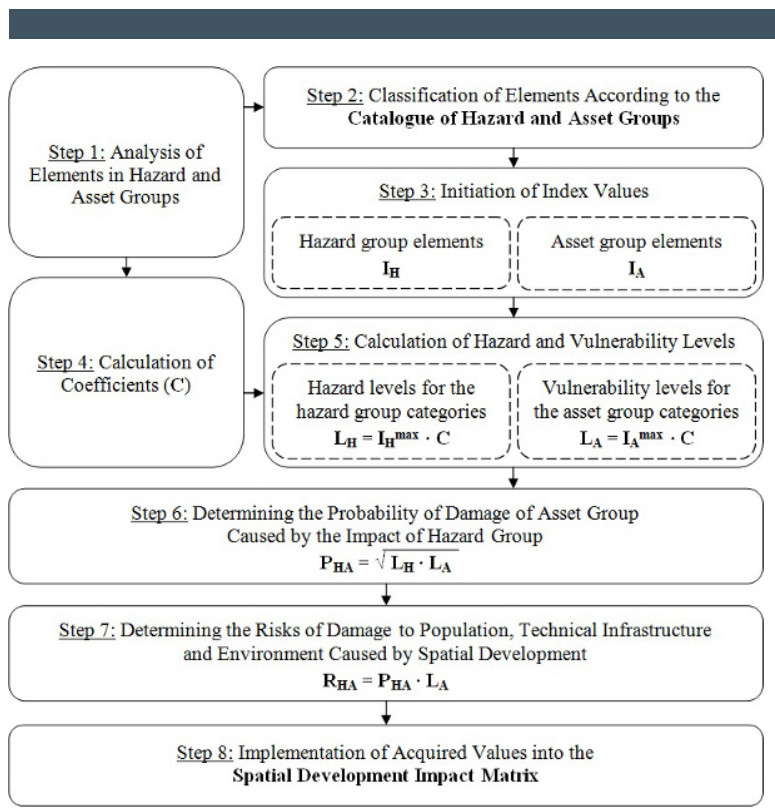

Figure 1. Assessment Process Algorithm.

development [32], and 2) the Group of Assets (which includes population, infrastructure and environment). The algorithm itself consists of individual steps which help determine potential risks that the Group of Asset will incur damages resulting from spatial development (see Figure 1).

\section{Step 1: Analysis of Elements in Hazard and Asset Groups}

The analysis of elements in the hazard and asset groups is the essential step in the assessment process algorithm. The analysis considers all social, technical, and environmental aspects of the planned spatial development as well as the potential negative impacts it has on population, technical infrastructure and the environment. This part of the analysis may be carried out using data obtained from territorial plans. The analysis of the elements of asset group located in the area where spatial development is to be implemented consists of identifying all elements within the subgroups (population, technical infrastructure and the environment) whose value may be reduced or completely lost due to the negative impacts. This analysis may use information from maps and particular state administration authorities (e.g. district fire rescue corps, regional government and municipal authorities).

Step 2: Classification of Elements According to the Catalogue of Hazard and Asset Groups

In the next step it is necessary to classify the elements according to the Catalogue of Hazard and Asset Groups, which consists of individual categories and their elements. 
There are the categories of hazard group (i.e. the individual negative aspects of spatial development) and the categories of asset group (i.e. categories of the population, technical infrastructure and environment).

Step 3: Initiation of Index Values of the Elements in Hazard and Asset Groups

Once the elements are classified into particular categories it is necessary to initiate the index values of the elements of hazard group $\left(I_{H}\right)$ and the elements of asset group $\left(I_{A}\right)$. Thus the elements are assigned corresponding index values.

\section{Step 4: Calculation of Coefficients}

Another step of the algorithm is the calculation of coefficients. The user adds selected criteria into preset formulae and then various coefficients are calculated for both the Hazard Group and the Asset Group. The final coefficients consider variables, such as range, frequency and probability.

Step 5: Calculation of Hazard and Vulnerability Levels The calculation of hazard levels for individual categories of hazard group $\left(L_{H}\right)$ and vulnerability levels for individual categories of asset group $\left(L_{A}\right)$ is made with the help of easy mathematical operations [33]. The level of each category $(\mathrm{L})$ is calculated as the product of maximum index value $\left(I^{\max }\right)$ of initiated elements belonging to the given category and particular coefficients $(C)$, i.e. $L=I^{\max } \cdot C$.

Step 6: Determining the Probability of Damage of Asset Group Caused by the Impact of Hazard Group

Determining the probability of damage $\left(\mathrm{P}_{\mathrm{HA}}\right)$ of asset group caused by the impact of hazard group starts from the logical reasoning that this probability is the highest if the category with the highest level of hazard has impact on the category with the highest level of vulnerability and vice versa. Mathematically, the probability of damage is determined by the goniometric averaging of hazard and vulnerability levels of the assessed categories $\left(P_{H A}=\sqrt{ } L_{H} \cdot \sqrt{ } L_{A}\right)$.

Step 7: Determining the Risks of Damage to Population, Technical Infrastructure and Environment Caused by Spatial Development

The last but one step in the assessment process is to determine the risks of damage to population, technical infrastructure and environment caused by spatial development $\left(R_{\mathrm{HA}}\right)$. The calculation of such risk is based on general platforms $[34,35]$. The level of risk is determined as the product of vulnerability level of particular category of asset group and the probability related to the assessed categories of hazard and asset groups $\left(R_{H A}=P_{H A} \cdot L_{A}\right)$.

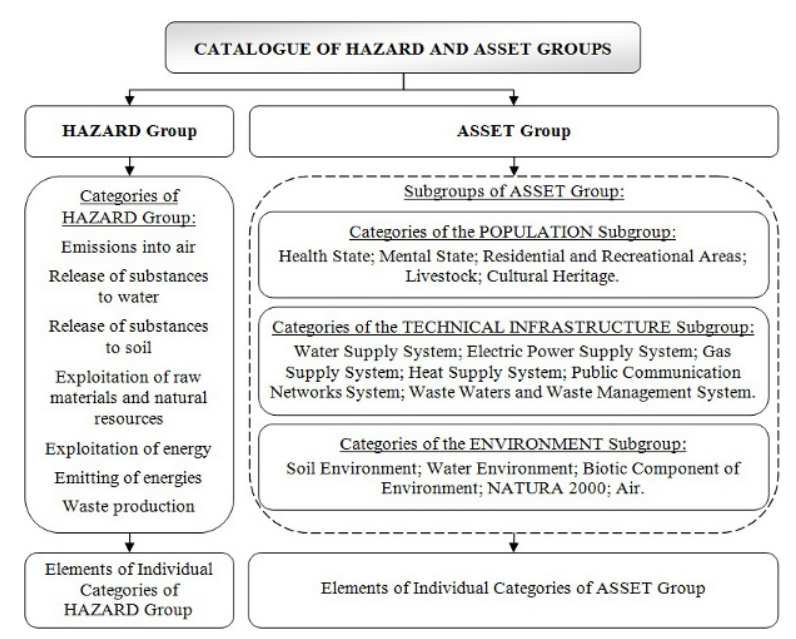

Figure 2. Catalogue of Hazard and Asset Groups.

Step 8: Implementation of Acquired Values into the Spatial Development Impact Matrix

The outcome of the assessment process will be the matrix presenting the potential level of risk for population, technical infrastructure and the environment caused by intended spatial development (see Section 3.3. Spatial Development Impact Matrix).

\subsection{Catalogue of Hazard and Asset Groups and Coefficients}

The Catalogue of Hazard and Asset Groups is a significant component of the spatial development security assessment method. It consists of individual categories and elements. These categories are classified into the categories of hazard group and the categories of asset group. Individual categories then include elements, to which appropriate index values are assigned. The index values consider their hazardousness (in case of hazard group elements) and vulnerability (in case of asset group elements). The structure of the Catalogue of Hazard and Asset Groups is shown in Figure 2.

Coefficients play a pivotal role in the assessment process. They account for variables, such as range, frequency and probability. It can be said that coefficients are regulators of possible deviations in hazard or vulnerability of the assessed elements. That is, for example, the increasing hazardousness of the element of spatial development in relation to the frequency of hazardous substances and waste management. Moreover, ensure more accurate outcomes in determining the levels of hazards and vulnerabilities in the individual categories of threat and asset groups. The coefficients are aimed to increase the levels of 
particular categories according to the current state of the variables. The coefficients may be divided into two categories, according to their relation to the groups of hazards and assets, as follows:

Coefficients related to the group of threats:

- Water or soil pollution burden $\left(\mathrm{C}_{\mathrm{WS}}\right)$;

- Frequency of energy emitting $\left(C_{E}\right)$;

- Frequency of hazardous substances management and waste management $\left(C_{P}\right)$;

Coefficients related to the group of assets:

- Current level of damage to the area of spatial development $\left(C_{D}\right)$.

\subsection{Spatial Development Impact Matrix}

The final risks of damage to population, technical infrastructure and the environment caused by the intended spatial development are in the final phase of assessment shown in the Spatial Development Impact Matrix (see Figure 3).

\begin{tabular}{|c|c|c|c|c|c|c|c|c|}
\hline \multirow{2}{*}{\multicolumn{2}{|c|}{$\begin{array}{l}\text { SPATIAL DEVELOPMENT } \\
\text { IMPACT MATRIX }\end{array}$}} & \multicolumn{7}{|c|}{ Potential Negative Aspects of Spatial Development } \\
\hline & & $A_{A}$ & $A_{W}$ & $\mathrm{~A}_{5}$ & $A_{R}$ & $\mathrm{~A}_{\mathrm{X}}$ & $\mathrm{A}_{\mathrm{E}}$ & $A_{p}$ \\
\hline \multirow{5}{*}{ 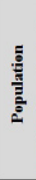 } & Health State & & & & & & & \\
\hline & Mental State & & & & & & & \\
\hline & $\begin{array}{l}\begin{array}{l}\text { Residential and Recreational } \\
\text { Areas }\end{array} \\
\end{array}$ & & & & & & & \\
\hline & Livestock & & & & & & & \\
\hline & Cultural Heritage & & & & & & & \\
\hline \multirow{6}{*}{ 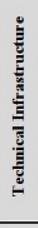 } & Water Supply System & & & & & & & \\
\hline & $\begin{array}{l}\text { Electric Power Supply } \\
\text { System }\end{array}$ & & & & & & & \\
\hline & Gas Supply System & & & & & & & \\
\hline & Heat Supply System & & & & & & & \\
\hline & $\begin{array}{l}\text { Public Communication } \\
\text { Networks System }\end{array}$ & & & & & & & \\
\hline & \begin{tabular}{|l|} 
Waste Waters and Waste \\
Management System \\
\end{tabular} & & & & & & & \\
\hline \multirow{5}{*}{ 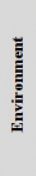 } & Soil Environment & & & & & & & \\
\hline & Water Environment & & & & & & & \\
\hline & \begin{tabular}{|l} 
Biotic Component of \\
Environment
\end{tabular} & & & & & & & \\
\hline & NATURA 2000 & & & & & & & \\
\hline & Air & & & & & & & \\
\hline
\end{tabular}

Figure 3. Spatial Development Impact Matrix.

Legend:

$\overline{A_{A}-\text { Emissions into air }}$

$A_{W}$ - Release of substances in water

$A_{S}$ - Release of substances into soil

$A_{R}-$ Exploitation of raw materials and natural resources

$A_{X}-$ Exploitation of energy

$A_{E}-$ Emitting of energy generation by-products

$A_{P}-$ Waste production
Note: The cross-hatched fields indicate that the aspect and category are not related and therefore the level of risk is not determined for this relation.

The outcome of the assessment process is the matrix presenting the potential level of risk for population, infrastructure and environment caused by intended spatial development. These risks will be classified in three categories. The description of individual risk categories and the determination of acceptability of potential risk as well as the measures to be taken (i.e. the recommendations which should be followed by the assessor) are as follows:

- Category A Risk Level: Spatial development has a low potential risk of damage to the environment in the assessed area (i.e. the risk is acceptable). Even potentially highly hazardous elements may be located in the given area when standard safety measures are followed. This category of risk is a necessary prerequisite for building new industrial facilities.

- Category B Risk Level: Spatial development indicates an increased potential risk of damage to the environment in the assessed area (it is necessary to reduce such a risk). It is not suitable to carry out the planned spatial development in the given area. It is recommended to look for another area or modify the spatial development plan so that it does not cause damage to the environment. At the same time it is recommended to reassess or re-plan the proposed spatial development.

- Category C Risk Level: Spatial development indicates a high potential risk of damage to the environment in the assessed area (the risk is unacceptable). This category indicates that it is the most probable that the planned spatial development will cause an extensive and serious damage to the environment in the given area. Therefore it is recommended not only to look for another, less vulnerable area, but also thoroughly check the range and level of hazard of the planned spatial development.

\section{Discussion and Conclusions}

Spatial development brings a number of risks and it may have negative impacts on balanced relations among spatial conditions and the environment, economic development and integrity of communities of population, and generally, on the sustainable development of a territory. Therefore, continually ensuring security is one of the primary conditions for successful spatial development [36]. 
Currently, there is no simple and universal tool for assessing the impact of spatial development on population, infrastructure and the environment in relation to the proposed plan. In this paper, we have proposed a means to add security provisions to spatial development plans utilizing a simple algorithmic procedure based on existing impact assessment methods and tools. The universality of the proposed algorithm lies in the fact that it can easily be optimized and implemented in various countries despite various legal regulations and variable values that pertain to areas in which further development is planned.

At present, the methods and tools of impact assessment are the best means for preventing the occurrence of activities with negative impacts on population and environment in areas of with high technological risk $[26,27]$. For this reason it is absolutely necessary to create and implement a similar tool of assessing the impact of spatial development.

It is important to mention that the SDIA tool is not intended to be developed as a directive mechanism, but only as an informative tool for providing recommendations to assessors on whether it is suitable to carry out the planned spatial development in a given area or not.

We are currently developing software that comprises the SDIA. Furthermore, we aim to provide means for visualizing the SDIA tool's outcomes in geographic information systems (GIS). These systems are generally considered to be the most adequate tools for displaying geographic elements, processes, and their inter-relations in areas of interest [37]. The GIS platform will contribute to the clearer interpretation of SDIA's acquired outcomes.

\section{Acknowledgments}

This work was conducted under the project of the Ministry of Interior of the Czech Republic filed under code VD20062010A06 and entitled "Research of New Principles and Methods in the Framework of Provisions for Population Protection, Crisis Management and Enhanced Preparedness of Integrated Rescue System (IRS) in case of Potential Effects of Chemical, Biological, Radiological, and Nuclear Weapons and other Dangerous Substances".

\section{References}

[1] Poggio L., Vršèaj B., Hepperle E., Schulin R., Marsan F.A., Introducing a method of human health risk evaluation for planning and soil quality management of heavy metal-polluted soils, LANDSC URBAN PLAN, 2008,88,64-72
[2] Spirn A.W., Landscape planning and the city, LANDSC URBAN PLAN, 1986,13,433-441

[3] Beardsley K., Thorne J.H., Roth N.E., Gao S., et al., Assessing the influence of rapid urban growth and regional policies on biological resources, LANDSC URBAN PLAN, 2009,93,172-183

[4] Mander Ü., Palang H., Ihse M., Development of European landscapes, LANDSC URBAN PLAN, 2004,67,1-8

[5] Weber Ch., Interaction model application for urban planning, LANDSC URBAN PLAN, 2003,63,49-60

[6] Jones H., Jones P., Cities and sustainability, LANDSC URBAN PLAN, 2007,83,1

[7] Pediaditia K., Doick K.J., Moffat A.J., Monitoring and evaluation practice for brownfield, regeneration to greenspace initiatives: A meta-evaluation of assessment and monitoring tools, LANDSC URBAN PLAN, 2010,97,22-36

[8] Termorshuizen J.W., Opdam P., Brink A., Incorporating ecological sustainability into landscape planning, LANDSC URBAN PLAN, 2007,79,374-384

[9] Potschin M.B., Haines-Young R.H., Landscapes and sustainability, LANDSC URBAN PLAN, 2006,75,155-161

[10] Leitão A.B., Ahern J., Applying landscape ecological concepts and metrics in sustainable landscape planning, LANDSC URBAN PLAN, 2002,59,6593

[11] Declaration of the United Nations Conference on the Human Environment, United Nations Environment Programme, Sweden, 1972

[12] Brundtland G.H., The Concept of Sustainable Development, In: Report of the World Commission on Environment and Development: Our Common Future (A/42/427), World Commission on Environment and Development, Greven, 1987

[13] Maier K., Rezac V., Economy in the Territory, 3rd ed., CVUT, Prague, 2006, (in Czech)

[14] Navratilova A., et al., Principles and Rules of Spatial Planning, 1st ed., Institute of Spatial Development, Brno, 2006, (in Czech)

[15] State Environmental Policy of the Czech Republic, 1st ed., Ministry of Environment, Prague, 2004, (in Czech)

[16] Strategy of Sustainable Development of the Czech Republic, 1st ed., Ministry of Environment, Prague, 2004, (in Czech)

[17] Act No 183/2006 Col. on the spatial planning and building code, Collection of Acts of the Czech Republic, (in Czech)

[18] Act No 114/1992 Col. on the protection of nature and landscape, Collection of Acts of the Czech Republic, (in Czech) 
[19] Müchera C.A., Hennekens S.M., Bunce R.G.H., Schaminée J.H.J., et al., Modelling the spatial distribution of Natura 2000 habitats across Europe, LANDSC URBAN PLAN, 2009,92,148-159

[20] Söderman T., Natura 2000 appropriate assessment: Shortcomings and improvements in Finnish practice, ENVIRON IMPACT ASSESS REV, 2009,29,7986

[21] Act No 100/2001 Col. on environmental impact assessment, Collection of Acts of the Czech Republic, (in Czech)

[22] Council Directive 85/337/EEC of 27th June 1985 on the assessment of the effects of certain public and private projects on the environment.

[23] Council Directive 97/11/EC of 3rd March 1997 amending Directive 85/337/EEC on the assessment of the effects of certain public and private projects on the environment

[24] Directive 2001/42/EC of the European Parliament and of the Council of 27th June 2001 on the assessment of the effects of certain plans and programmes on the environment

[25] Senovsky M., Senovsky P., Decision Making in the Protection of Critical Infrastructure, SPEKTRUM, 2008,8,11-13, (in Czech)

[26] Bartlova I., Balog K., Hazard analysis and prevention of industrial accidents I. 2nd ed., SPBI, Ostrava, 2007, (in Czech)

[27] Senovsky M., Adamec V., Krocova S., Senovsky P., Assessment of Risks of Critical Infrastructure Elements, SPEKTRUM, 2009,9,57, (in Czech)

[28] Dow's Fire \& Explosion Index Hazard Classification Guide (FEI), 7th ed., American Institute of Chemical Engineers, New York, 2005

[29] Vojkovska K., Danihelka P., Methodology for the environmental impact analysis of accidents involving haz- ardous substances (Hazard \& Vulnerability Index), 1st ed., VSB - Technical University, Ostrava, 2002, (in Czech)

[30] Rehak D., Dvorak J., The Method of Preventive Military Training Environmental Impact Assessment (Hazard \& Impact Index) - Final Report on the progress made on the Grant project KJB606070701, Academy of Sciences of the Czech Republic, Prague, 2010, (in Czech)

[31] Rehak D., Dvorak J., Novotna L., Komar A., Methodical Instructions for Providing the Environmental Security of Military Training Activities Conducted Outside Military Training Areas - Certified methodology, Ministry of Defence Logistic Section, Prague, 2010, (in Czech)

[32] ISO 14004, Environmental management systems General guidelines on principles, systems and support techniques, 2004

[33] Riha J., et al., Vulnerability of Infrastructure and Environmental Systems, SPEKTRUM, 2008,8,22-27 (in Czech)

[34] ISO 31000, Risk management - Principles and guidelines, 2009

[35] Grasseova M., Dubec R., Rehak D., Analysis of the enterprise at the hands of managers: 33 most frequently applied methods of the strategic management, 1st ed., Computer Press, Brno, 2010

[36] Kozlowski J.M., Sustainable development in professional planning: a potential contribution of the EIA and UET concepts, LANDSC URBAN PLAN, 1990,19,307332

[37] Hrdina P., Kotatko A., Dobes P., Territorial Unit Risk Analysis with the Use of Geographic Information Systems, SPEKTRUM, 2010,10,25-29, (in Czech) 